\title{
Access to Adequate Outpatient Depression Care for Mothers in the US: A Nationally Representative Population-Based Study
}

\author{
Whitney P. Witt, PhD, MPH ${ }^{\dagger}$, Abiola Keller, MPAS, PA-C ${ }^{\dagger}$, Carissa Gottlieb, MS ${ }^{\dagger}$, Kristin \\ Litzelman, BA ${ }^{\dagger}$, John Hampton, MS $^{\dagger}$, Jonathan Maguire, BA ${ }^{\ddagger}$, and Erika W. Hagen, PhD, \\ MS $^{\dagger}$ \\ tDepartment of Population Health Sciences, School of Medicine and Public Health, University of \\ Wisconsin, Madison \\ ‡Independent Statistical Consultant, Santa Barbara, CA, maguire_jonathan@hotmail.com
}

\begin{abstract}
Maternal depression is often untreated, resulting in serious consequences for mothers and their children. Factors associated with receipt of adequate treatment for depression were examined in a population-based sample of 2,130 mothers in the USA with depression using data from the 1996-2005 Medical Expenditure Panel Survey. Chi-squared analyses were used to evaluate differences in sociodemographic and health characteristics by maternal depression treatment status (none, some, adequate). Multivariate regression was used to model the odds of receiving some or adequate treatment, compared to none. Results indicated that only $34.8 \%$ of US mothers with depression received adequate treatment. Mothers not in the paid workforce and those with health insurance were more likely to receive treatment, while minority mothers and those with less education were less likely to receive treatment. Understanding disparities in receipt of adequate treatment is critical to designing effective interventions, reducing treatment inequities, and ultimately improving the mental health and health of mothers and their families.
\end{abstract}

\section{Keywords}

Maternal Depression; Access to treatment for depression; Adequacy of treatment for depression; Disparities in treatment for depression; population-based study; Medical Expenditure Panel Survey (MEPS)

\footnotetext{
All communications should be directed to: Whitney P. Witt, PhD, MPH Assistant Professor Department of Population Health Sciences School of Medicine and Public Health University of Wisconsin, Madison 610 North Walnut Street, Office 503 Madison, WI 53726 Phone: 608- 265-6290 Fax: 608-263-2820 wwitt@wisc.edu Whitney P. Witt, PhD, MPH Assistant Professor Department of Population Health Sciences School of Medicine and Public Health University of Wisconsin, Madison 610 North Walnut Street, Office 503 Madison, WI 53726 Phone: 608- 265-6290 Fax: 608-263-2820 wwitt@ wisc.edu Abiola Keller, MPAS, PA-C Department of Population Health Sciences School of Medicine and Public Health University of Wisconsin - Madison 610 Walnut Street, WARF 636 Madison, WI 53726 Phone: 608-262-7278 Fax: 608-262-2820 aokeller@wisc.edu Carissa Gottlieb, MS Assistant Researcher Department of Population Health Sciences School of Medicine and Public Health University of Wisconsin - Madison 610 Walnut Street, WARF Office 660 Madison, WI 53726 Phone: 608- 265-3687 cagottlieb@wisc.edu Kristin Litzelman, BA Department of Population Health Sciences School of Medicine and Public Health University of Wisconsin - Madison 610 Walnut Street, WARF-558 Madison, WI 53726 Phone: 608-263-5987 litzelman@ wisc.edu John M. Hampton, MS University of Wisconsin 610 Walnut St, WARF Room 307 Madison, WI 53726 Phone: 608-262-9627 Fax: 608-265-5330 jmhampto@ wisc.edu Jonathan Maguire 715 Willow Ave. \#4 Hoboken, NJ 07030 Phone: 201-850-1169 Maguire_jonathan@yahoo.com Erika W. Hagen, Ph.D., MS Department of Population Health Sciences School of Medicine and Public Health University of Wisconsin - Madison 610 Walnut Street, WARF 634 Madison, WI 53726 Phone: 608-265-3296 Fax: 608-262-2820 ewarkentien@wisc.edu.

Work was completed at: Department of Population Health Sciences School of Medicine and Public Health University of WisconsinMadison 610 North Walnut Street Madison, WI 53726
} 


\section{Introduction}

Maternal depression is a major public health issue, often with long term adverse health outcomes for mothers and their families. Women with depression are more likely to engage in poor personal health behaviors, including smoking, lack of exercise, and sexual risk taking. ${ }^{1}$ Among mothers, depression and adverse risk behaviors not only have important consequences for women's own health, but may also have a profound negative impact on the long-term health, quality of life, and well-being of their children. ${ }^{2-5}$

Even though depression is a common and treatable disorder, adults are often underdiagnosed and undertreated ${ }^{6-8}$ and most women go without treatment. ${ }^{9}$ Clinical studies show that treatment for depression can improve the mental health status of adults in general. 10-13 Compelling results from the Sequenced Treatment Alternatives to Relieve Depression (STAR-D) study underscore the importance of treating maternal depression, as it can lead to remission and reduce children's mental health symptoms and diagnoses. ${ }^{14}$ Therefore, access to treatment for maternal depression is critical in improving maternal mental health and reducing the impact of depression on the family.

Despite this compelling evidence, little is known about maternal depression on a national level. Prior studies of the treatment of maternal depression have been clinic-based and conducted on convenience samples or among mothers who are receiving health care services. The referral patterns underlying the care that these women receive may limit the generalizability of the findings from these studies. ${ }^{15}$

Recent research has recognized the importance of considering not only the receipt but also the adequacy of depression treatment. ${ }^{16,17}$ Adequate treatment refers to the minimum amount of care necessary to reduce and remove all signs and symptoms of depression, restore occupational and psychosocial function, and reduce the likelihood of relapse and recurrence..$^{18}$ However, no population-based study of mothers has directly examined the relationship between depression and access to adequate treatment for depression.

This paper uses the Aday and Anderson, or "behavioral model", which characterizes the determinants of healthcare use as need, enabling, and predisposing factors. ${ }^{19,}{ }^{20}$ Need factors include medically evaluated and self-perceived health problems and symptomotology; enabling factors refer to resources available to the individual or community, such as health insurance; and predisposing factors include an individual's demographic characteristics and health beliefs. ${ }^{20}$ For this study, poor mental health is considered a potential need factor in the behavioral model.

This study sought to address gaps in the literature by examining access to adequate treatment for maternal depression within a population based sample. Further, this study determined if disparities exist in accessing adequate treatment for maternal depression and explored whether particular subgroups may be at risk for receiving inadequate treatment. As a secondary aim, interactions between covariates were tested to gain greater insight into the relationship between the predisposing, enabling, and need factors and access to adequate treatment.

\section{Methods}

\section{Study Design, Population, and Data Sources}

Data are from the Medical Expenditure Panel Survey (MEPS), a nationally representative sample of the civilian noninstitutionalized population in the United States. MEPS uses an overlapping panel design to collect person and household data at 5 different time points (or 
rounds) throughout a 2-year period. Complete data from 10 panels of the 1996 to 2005 MEPS were pooled through a public use linkage file prior to analyses. Detailed methodology and a description of data available in MEPS are available at http://www.meps.ahrq.gov.meps.web.

The sample includes 2,130 mothers with depression who were interviewed about their health in one of ten panels of the 1996-2005 MEPS. Mothers were identified as MEPS interviewees with at least one child (0-17 years). Subjects were excluded from the dataset if they had missing information on age, race, family size, education level, insurance type, marital status, employment status, region of the U.S., Metropolitan Statistical Area (MSA), poverty status, functional limitations, health and mental health, or a zero person weight.

Identification of Mothers with Depression-Mothers with depression were identified through the Household Component or respondent interview of the MEPS, where in the Condition Enumeration Section household respondents were asked if they had experienced any "health problems.... as well as mental or emotional health conditions, such as feeling sad, blue, or anxious about something." 21 Truncated 3-digit International Classification of Diseases, Ninth Revision (ICD-9) codes were generated from the respondent interview. Mothers with an ICD-9 code of 296 or 311, during any round, were identified as having depression. While code 296 includes major depressive disorder and other episodic mood disorders, over $94 \%$ of mothers with depression in the sample were identified using code 311 (depression unspecified).

\section{Measures}

The variables described in this section are organized by the domains of the behavioral model which are thought to influence mothers' use of treatment for depression: predisposing, enabling, and need factors.

Predisposing Factors-The following maternal demographic characteristics were included in the analyses: maternal age (14-34, 35-44, 45+), race/ethnicity (White nonHispanic; Black non-Hispanic; Other non-Hispanic; and Hispanic), education status (no or some high school, high school graduate, some college, and college graduate or beyond), maternal participation in the paid workforce, single parent household status, family size (less than or greater than 4 people), urbanicity (urban versus rural by Metropolitan Statistical Area (MSA) status), and region of the US (West, Northeast, Midwest, and South) as defined by USA Census regions.

Enabling Factors-Health insurance status was grouped in the following mutually exclusive categories: no health insurance, any publicly funded health insurance (Medicaid and/or Medicare), and private health insurance only. The poverty threshold level (percent of poverty threshold: below $100 \%, 100-199 \%, 200-399 \%$, and $400 \%$ and higher) was also examined as an enabling factor to access to treatment.

Need Factors-The following need factors were examined in the analyses: self-rated mental health status, self-rated health status, other mental health and chronic medical conditions, and functional limitation status.

Self-Rated Mental Health Status: Mothers were asked to rate their mental health at every round of the MEPS by responding to the question "In general, would you say that your mental health is excellent, very good, good, fair, or poor?" A dichotomous variable was used in the statistical analyses, comparing mothers reporting fair or poor mental health in any round to mothers reporting excellent, very good, or good mental health in all rounds. 
Self-rated Health Status: Mothers were asked to rate their health at every round of the MEPS by responding to the question "In general, would you say that your health is excellent, very good, good, fair, or poor?" A dichotomous variable was used in the statistical analyses, comparing mothers reporting fair or poor health in any round to mothers reporting excellent, very good, or good health in all rounds.

Other Mental Health and Chronic Medical Conditions: Other mental health and chronic medical conditions were identified using truncated 3-digit ICD-9 codes generated from the respondent interview, where mothers were asked if they had experienced any chronic medical conditions (cancer, diabetes, chronic bronchitis, emphysema or chronic obstructive pulmonary disease, high cholesterol, HIV/AIDS, primary hypertensive disease, ischemic heart disease , stroke, arthritis, asthma, gall bladder disease, stomach ulcers, or back problems of any kind) or other mental health problems (alcohol or drug abuse, psychotic conditions, anxiety conditions, adjustment disorders or short-term reactions to stress, or personality disorders). A dichotomous variable was constructed to identify mothers with complications of pregnancy, childbirth, and the puerperium period.

Functional Limitation Status: Mothers were classified as having a functional limitation if they reported limitations (because of an impairment or a physical or mental health problem) in any one of the following categories: 1) work, 2) housework, 3) school, 4) social activities, or 5) cognitive abilities. A count of functional limitations was created based on how many of the five individual limitations each mother reported, categorized as 0 limitations, 1 limitation, and 2-5 limitations.

\section{Outcome Variable}

Treatment of Maternal Depression: Treatment of maternal depression was defined using annualized information about mothers' prescription medications and psychotherapy. The MEPS Prescription Medication File was used to identify whether mothers had received prescriptions for medications indicated for the treatment of depression, as set forth by the National Committee for Quality Assurance, Health Plan Employer Data and Information Set list of National Drug Codes for antidepressant medication management. ${ }^{22}$ The MEPS Outpatient Department Visits File and MEPS Office-Based Medical Provider Visits File were used to determine if mothers had any visits involving psychotherapy. It was assumed that prescriptions were for a minimum of 30 days and psychotherapy visits were for a minimum of 30 minutes.

These two types of treatment, pharmacotherapy and psychotherapy, were used to construct an index of the level of "adequacy" of the type and duration of treatment based on evidencebased treatment guidelines. ${ }^{18,23}$ Three mutually exclusive categories were defined: 1) no treatment; 2) some treatment; and 3) adequate treatment for depression. Mothers with depression who reported no pharmacotherapy or psychotherapy over the course of the year were categorized as receiving "no treatment." Mothers who reported any use of the identified medications or who reported using outpatient or office-based services as such were considered to have received "some treatment" for depression over the year. "Adequate treatment" was defined as receipt of either: 1) at least four anti-depression-related prescriptions or 2) at least eight outpatient or office-based psychotherapy or counseling

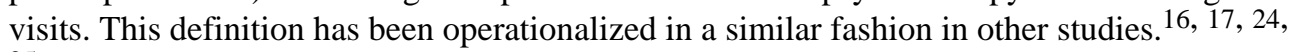
25

\section{Analytic Approach}

SAS 9.2 (SAS Institute Inc, Cary, NC) was used to construct the analytic files and STATA 10.1 (StataCorp LP, College Station, Tex) was used to perform all analyses, accounting for 
the complex design of the MEPS. The standard errors were corrected due to clustering within strata and the primary sampling unit. Survey weights were applied to produce estimates that account for the complex survey design, unequal probabilities of selection, and survey non-response.

Descriptive Analysis-Chi-squared analyses were used to test for differences in sociodemographic and health characteristics by maternal depression treatment status. If differences were found in the overall chi-square tests, each subgroup was tested for statistical significance.

Multivariate Analysis-For the regression analysis, a model was fit to identify the factors that were associated with the adequacy of treatment of maternal depression. One polychotomous logistic regression model was used to examine the odds of receiving adequate treatment or some treatment, as compared with no treatment. All variables were entered into the model simultaneously.

The Wald test was used to test the significance of four interactions between mothers' participation in the paid workforce and a) health insurance status; b) poverty threshold level; and c) education level. In addition, the interaction between race/ethnicity and health insurance status was tested.

\section{Results}

Overall, $9.5 \%$ of US mothers reported depression. Among mothers with depression, 37.9\% did not receive any treatment, $27.3 \%$ received some treatment, and $34.8 \%$ received adequate treatment for depression over the course of the year.

Significant differences were found in treatment status by sociodemographic and health characteristics (Table 1). Compared with mothers not receiving adequate treatment for depression, adequately treated mothers were more likely to be 35 years or older, White (nonHispanic), or have completed some college or beyond. They were also less likely to be in the paid workforce and more likely to be living in a two-parent household or living at $400 \%$ or above the poverty threshold. Among those who reported having private health insurance, significantly more mothers received adequate care than no care. Mothers with depression were more likely to receive adequate treatment if they reported co-morbid mental health problems, functional limitations, or poor perceived mental health status.

A multinomial logistic regression model was used to examine characteristics associated with mothers' receipt of some treatment or adequate treatment in reference to mothers who did not receive treatment (Table 2). The multivariate results are presented using the behavioral model as a framework.

\section{Predisposing Factors}

Results indicate that black (non-Hispanic) and other (non-Hispanic) mothers were less likely to receive some treatment (60\% and 33\%, respectively) compared with their white (nonHispanic) counterparts. In addition, black (non-Hispanic) mothers were nearly $80 \%$ less likely to receive adequate treatment than their White (non-Hispanic) counterparts. Hispanic and other minority mothers were less likely to receive adequate treatment as well. Compared with mothers who did not complete high school, mothers who were high-school graduates were significantly more likely to receive adequate treatment. Mothers with some college education were more than twice as likely to receive adequate treatment as non-high school graduates and mothers who completed college or additional schooling were nearly 3 times as likely to receive adequate care. Mothers not in the paid workforce were about 1.5 times 
more likely to receive some treatment and almost twice as likely to receive adequate treatment as those in the paid workforce. Mothers in the Northeast, Midwest, and South were all more likely to receive adequate treatment than those in the Western region of the US.

\section{Enabling Factors}

Mothers with either private or public health insurance were approximately twice as likely to receive some treatment compared to those without insurance. Compared to uninsured mothers, these mothers were over 3 times more likely to receive adequate treatment. The poverty threshold was not significantly associated with access to treatment.

\section{Need Factors}

Mothers who had comorbid mental health conditions were more likely to receive some or adequate treatment than those without another mental health condition. Mothers with depression who had multiple functional limitations were about twice as likely to receive some care and about 3 times more likely to receive adequate care than mothers with no or one functional limitation. Mothers with poor perceived mental health were more likely to receive adequate treatment, but no more likely to receive some treatment.

In the final analysis, interactions between mothers' participation in the paid workforce and a) health insurance status; b) poverty threshold level; and c) education level were assessed. This was done in order to determine if these covariates modified the relationship between workforce participation and receipt of adequate treatment. In addition, the interaction between race/ethnicity and health insurance status was tested in order to examine if health insurance modified the relationship between race/ethnicity and receipt of adequate treatment. None of these interactions were statistically significant.

\section{Discussion}

This national study of access to outpatient treatment for maternal depression contributes important new findings to the literature. While this study found that most mothers with depression in the US received some form of treatment for depression, more than $65 \%$ of mothers who reported being depressed did not receive adequate treatment for their disease. Notably, this study shows that significant employment, racial, ethnic, educational, insurance-related, and geographic disparities exist in the receipt of adequate treatment for maternal depression.

First, mothers in the paid workforce were less likely to receive treatment. While previous studies have also reported an association between being employed and lower mental healthcare use, ${ }^{26,27}$ this study clarifies that mothers in the paid workforce were less likely to receive both any and adequate treatment. Long work hours limit employees' ability to interact with the healthcare system, ${ }^{28}$ and women specifically report that they delay or go without healthcare because they are unable to take time off work or have child care problems. ${ }^{29}$ Although employer sponsored counseling services, such as Employee Assistance Programs (EAP) are effective, widely available depression treatment strategies, 30,31 they tend to be underutilized due to employee unawareness or confidentiality concerns. ${ }^{32,} 33$ In addition, EAPs differ dramatically in the services they offer ${ }^{34}$ and primarily provide short-term counseling and/or referrals for additional care. ${ }^{35}$ Standardization and positive promotion of EAP benefits may improve depression intervention for working mothers who lack the time or resources to access mental health care from another source. 
Additionally, this study found that black (non-Hispanic) and other (non-Hispanic) mothers were less likely to get any treatment and all minority mothers were less likely to get adequate treatment than White (non-Hispanic) mothers. While the differences found in this study may be due to racial bias, evidence for this in mental healthcare is conflicting. Research shows that provider bias occurs in the medical setting ${ }^{36,37}$ and while it is plausible that these findings may extend to the mental healthcare setting, one study found provider bias did not have an effect on diagnosis and management of late-life depression. ${ }^{38}$ Treatment initiation and patient-provider communication may also influence receipt of adequate care by minorities. ${ }^{16,}{ }^{39}$ Studies show that there are ethnic and racial differences in help-seeking behavior, the use of informal support networks, and treatment preferences among women and mothers. ${ }^{40-45}$ In order to better understand the disparity seen in the adequacy of depression treatment between White and minority mothers, it will be important to focus on barriers to treatment initiation and the possible role of racial bias and patientprovider communication.

Consistent with previous studies, ${ }^{46-48}$ these results indicate mothers with a higher level of education, worse self-reported mental health, or comorbid mental health conditions were more likely to receive treatment. While the relationship between education and the likelihood of some treatment was not significant, a trend between increasing education and the receipt of adequate treatment was observed. More highly educated mothers may be more health literate and have increased knowledge about the diagnosis of depression and the importance of adequate treatment. They may also be better equipped with the knowledge and skills necessary to interact with the health care system. Mothers with depression and low educational attainment are a subgroup at risk for not receiving adequate treatment and may benefit from interventions to improve their health literacy.

Mothers with either public or private insurance were more likely to get some treatment or adequate treatment as compared with their uninsured counterparts. Although these findings suggest the importance of insurance coverage in the receipt of some and adequate mental health treatment for mothers, the generosity of mental healthcare benefits could not be explored. Other national studies have also found that private and public health insurance increases use of mental health services, ${ }^{46}$ yet in this study more than $80 \%$ of mothers who did not receive any treatment reported having insurance. This finding demonstrates that having health insurance does not automatically ensure the receipt of high-quality care. Key points of vulnerability in the health care system at which the gap between access to insurance coverage and delivery of high-quality health services can widen have been identified. ${ }^{49}$ Future research is needed to examine these points of vulnerability and other barriers to receiving treatment among mothers with insurance.

Finally, important differences were found in the receipt of adequate treatment for maternal depression by geographic region of the US. Consistent with previous studies of regional variation in receipt of general health care, ${ }^{50}$ mothers residing in the West were significantly less likely to receive adequate treatment for depression than mothers residing in all other regions. Regional variation in the receipt of adequate care may reflect patient preferences, provider bias, or disparities in access to primary care, which is the source of treatment for at least $30 \%$ of people with depression. ${ }^{51,52}$ Alternatively, regional variation could reflect differences in practice patterns, medical culture, or available technology. While no known study specifically demonstrates this, such differences have been previously observed with other primary care services. ${ }^{50}$ Addressing the causes of regional variation in receiving adequate treatment for maternal depression is an important objective for researchers and policy makers alike. 
Mothers' under and untreated depression could adversely impact the health and well-being of their family members, particularly children. Numerous clinical studies consistently have shown that parental clinical depression is associated with children's psychiatric and other morbidity, ${ }^{4,}, 53-57$ poor health status and development, ${ }^{58-60}$ worse prevention practices for children (i.e., not using a car seat), ${ }^{61,62}$ and increased use and costs of pediatric health and mental health care. ${ }^{59,60,63,64}$ Moreover, similar findings have been reported on the impact of poor mental health on spouses and other family members. ${ }^{65,} 66$

This study has several limitations. First, the measure of treatment adequacy was based on American Psychiatric Association (APA) guidelines and captured only the use of treatment. Therefore the quality of or adherence to prescribed treatment plans could not be assessed. Moreover, the type and duration of each psychotherapy or mental health counseling session could not be assessed in this study which limits the ability to determine the quality of the treatment. Additionally, depression treatment measurements were annualized and therefore these analyses could not examine the length of treatment time. Second, mothers with depression were identified through household informant reports instead of clinical diagnoses and therefore these results may not be generalizable to diagnosed patients. Finally, specific information about depression severity could not be measured in this analysis. However, general measures of functional status, comorbid mental health, and chronic medical conditions were included to address this issue.

This study has important strengths. First, the results are based on national, population-based data, providing policy-makers and practitioners with a picture of the groups of mothers who are not receiving adequate treatment for their depression. Additionally, due to the large sample size and rich data set that 10 years of the MEPS provided, several key predictors of depression treatment could be investigated together in one model, allowing for adjusted estimates of the contributing effect of each characteristic.

\section{Conclusions}

In conclusion, this study extends previous clinical and population-based research on access to treatment for maternal depression by examining access to adequate depression care in a nationally representative population-based sample of mothers. The findings show that most mothers with depression do not receive adequate treatment for their condition, underscoring the importance of examining adequate versus any care. For these mothers, having health insurance facilitates access to treatment. This study clarifies that employment, racial, ethnic, educational, and geographic disparities exist in the receipt of adequate treatment for maternal depression. Understanding these barriers to treatment is critical to designing effective interventions, reducing inequities, and ultimately improving the long-term mental health and health of mothers and their families. Future research studies are needed to establish if the differences in the type and duration of treatment among mothers with depression are due to patient preferences or provider and systematic biases. More specifically studies are needed to determine if these differences are avoidable, unfair, and unjust.

\section{Implications for Behavioral Health}

The study's main findings have important policy, clinical, and long-term behavioral health implications for mothers with depression. Ensuring that these mothers have insurance coverage for mental health services is important for obtaining adequate depression care. Additionally, employers may want to expand EAP programs to help both with the identification and treatment of maternal depression. The workplace may be a particularly effective target for interventions focusing on providing adequate mental health treatment to 
mothers in the paid workforce. Employers are poised to provide these services and stand to benefit from the improved mental health of their workforce, due to increased productivity and decreased absenteeism. ${ }^{67}$ Moreover, mothers and their providers may need to be better informed about symptoms of depression, treatment regimens, and long-term consequences of under-treating or not treating maternal depression. Overall, strategies to address disparities in the receipt of adequate depression care must be an integral component of maternal depression interventions in order to improve the long-term mental health and health of mothers and their families.

This study also has important implications for behavioral health research. This nationallyrepresentative study of mothers with depression augments the current literature by demonstrating that most mothers with depression do not receive adequate treatment for their condition even though many mothers receive at least some treatment. Future studies should consider the adequacy of treatment rather than simply whether any treatment has been received. Moreover, future work will need to specifically explore the role of benefit plan design in the timely receipt of adequate care, as the generosity of insurance coverage is likely to influence access to these services.

\section{Acknowledgments}

This research was supported in part by grants from the Agency for Healthcare Research and Quality (T32 HS00063 to the Harvard Pediatric Health Services Research Fellowship Program (W.P. Witt); T32 HS00083 Pre-doctoral NRSA Training Grant (A. Keller)), the National Institutes of Health (T32 HD049302 (E. W. Hagen)), and a Young Investigators Award from the Ambulatory Pediatrics Association (to W.P. Witt). We would also like to acknowledge the contribution of Aimee Teo Broman, MA for her assistance with the statistical analyses for this paper.

\section{References}

1. Allgower A, Wardle J, Steptoe A. Depressive symptoms, social support, and personal health behaviors in young men and women. Health Psychology. May; 2001 20(3):223-227. [PubMed: 11403220]

2. Gaynes BN, Burns BJ, Tweed DL, Erickson P. Depression and health-related quality of life. Journal of Nervous and Mental Disease. Dec; 2002 190(12):799-806. [PubMed: 12486367]

3. Hays RD, Wells KB, Sherbourne CD, Rogers W, Spritzer K. Functioning and well-being outcomes of patients with depression compared with chronic general medical illnesses. Archives of General Psychiatry. Jan; 1995 52(1):11-19. [PubMed: 7811158]

4. Lee CM, Gotlib IH. Maternal depression and child adjustment: a longitudinal analysis. Journal of Abnormal Psychology. Feb; 1989 98(1):78-85. [PubMed: 2708645]

5. Schwartz CE, Dorer DJ, Beardslee WR, Lavori PW, Keller MB. Maternal expressed emotion and parental affective disorder: risk for childhood depressive disorder, substance abuse, or conduct disorder. Journal of Psychiatric Research. 1990; 24(3):231-250. [PubMed: 2266512]

6. Kessler RC, Merikangas KR, Wang PS. Prevalence, comorbidity, and service utilization for mood disorders in the United States at the beginning of the twenty-first century. Annual Review of Clinical Psychology. 2007; 3:137-158.

7. Kocsis JH, Gelenberg AJ, Rothbaum B, et al. Chronic forms of major depression are still undertreated in the 21st century: Systematic assessment of 801 patients presenting for treatment. Journal of Affective Disorders. Feb 11.2008

8. Young AS, Klap R, Sherbourne CD, Wells KB. The quality of care for depressive and anxiety disorders in the United States. Archives of General Psychiatry. Jan; 2001 58(1):55-61. [PubMed: 11146758]

9. Robins, L.; Locke, B.; Reiger, D. An Overview of Psychiatric Disorders in America. In: Robins, L.; Reiger, D., editors. Psychiatric Disorder in America. The Free Press; New York: 1991.

10. Berber MJ. Pharmacological treatment of depression. Consulting with Dr Oscar. Canadian Family Physician. 1999; 45:2663-2668. [PubMed: 10587774] 
11. Citrome L. Management of depression. Current options for this highly treatable disorder. Postgraduate Medicine. 1994; 95(1):137-142. 145. [PubMed: 8278295]

12. von Knorring L. Depression--a serious, lifelong but treatable illness. Nordisk Medicin. 1996; 111(8):259-263. [PubMed: 8966104]

13. Katzelnick DJ, Simon GE, Pearson SD, et al. Randomized trial of a depression management program in high utilizers of medical care. Archives of Family Medicine. Apr; 2000 9(4):345-351. [PubMed: 10776363]

14. Weissman MM, Pilowsky DJ, Wickramaratne PJ, et al. Remissions in maternal depression and child psychopathology: a STAR*D-child report. Jama. Mar 22; 2006 295(12):1389-1398. [PubMed: 16551710]

15. Berkson J. Limitations of the application of fourfold table analysis to hospital data. Biometrics Bulletin. 1946; 2:47-53. [PubMed: 21001024]

16. Harman JS, Edlund MJ, Fortney JC. Disparities in the adequacy of depression treatment in the United States. Psychiatric Services. Dec; 2004 55(12):1379-1385. [PubMed: 15572565]

17. Kessler RC, Berglund P, Demler O, et al. The epidemiology of major depressive disorder: results from the National Comorbidity Survey Replication (NCS-R). Jama. Jun 18; 2003 289(23):30953105. [PubMed: 12813115]

18. AHCPR. Depression in Primary Care: Volume 2. Treatment of Major Depression. Rockville, MD: U.S. Department of Health and Human Services, Public Health Service, Agency for Health Care Policy and Research; 1993.

19. Andersen, RM. Behavioral Model of Families' Use of Health Services. Center for Health Administration Studies, University of Chicago; Chicago: 1968. Series No. 25

20. Andersen RM. Revisiting the behavioral model and access to medical care: does it matter? Journal of health and social behavior. Mar; 1995 36(1):1-10. [PubMed: 7738325]

21. AHRQ. Medical Expenditure Panel Survey (MEPS). [Accessed September 9th, 2008]. http://www.meps.ahrq.gov/mepsweb/survey_comp/hc_survey/2005/CE95.htm

22. NCQA. HEDIS® 2004 Final NDC Lists: Antidepressant Medication Management. [Accessed 2/10/05, 2005]. 2004 http://www.ncqa.org/Programs/HEDIS/hedis2004NDCFinalLists.htm

23. APA. Practice Guideline for Treatment of Patients with Major Depressive Disorder. American Psychiatric Association; Washington, DC: 2000.

24. Harman JS, Edlund MJ, Fortney JC, Kallas H. The influence of comorbid chronic medical conditions on the adequacy of depression care for older Americans. Journal of the American Geriatrics Society. Dec; 2005 53(12):2178-2183. [PubMed: 16398906]

25. Wang PS, Berglund P, Kessler RC. Recent care of common mental disorders in the United States : prevalence and conformance with evidence-based recommendations. Journal of General Internal Medicine. May; 2000 15(5):284-292. [PubMed: 10840263]

26. Elhai JD, Ford JD. Correlates of mental health service use intensity in the national comorbidity survey and national comorbidity survey replication. Psychiatric Services. 2007; 58(8):1108-1115. [PubMed: 17664523]

27. Olfson M, Klerman GL. Depressive symptoms and mental health service utilization in a community sample. Social Psychiatry and Psychiatric Epidemiology. 1992; 27(4):161-167. [PubMed: 1411743]

28. Fell DB, Kephart G, Curtis LJ, et al. The relationship between work hours and utilization of general practitioners in Four Canadian Provinces. Health Services Research. 2007; 42(4):14831498. [PubMed: 17610434]

29. Salganicoff, A.; Ranji, U.; Wyn, R. Women and Health Care: A National Profile. Kaiser Family Foundation; Menlo Park: July. 2005

30. Horwitz, SM.; Bell, J.; Grusky, R. The failure of community settings for the identification and treatment of depression in women with young children. In: Fisher, WH., editor. Research on community-based mental health services for children and adolescents. Elsevier Science/JAI Press; US: 2007. p. 13-31.

31. Sprang G. Utilizing a brief EAP-based intervention as an agent for change in the treatment of depression. Employee Assistance Quarterly. 1992; 8(2):57-65. 
32. Charbonneau A, Rosen AK, Ash AS, et al. Measuring the quality of depression care in a large integrated health system. Medical Care. May; 2003 41(5):669-680. [PubMed: 12719691]

33. Walton L. Exploration of the attitudes of employees towards the provision of counselling within a profit-making organisation. Counselling \& Psychotherapy Research. Mar; 2003 3(1):65-71.

34. Normand, J.; Lempert, RO.; O'Brien, CP. Under the influence? : drugs and the American work force. National Academy Press; Washington, D.C.: 1994.

35. Employee Assistance Professionals Association. EAPA STANDARDS AND PROFESSIONAL GUIDELINES FOR EMPLOYEE ASSISTANCE PROGRAMS. Arlington, VA: 2003.

36. Schulman KA, Berlin JA, Harless W, et al. The effect of race and sex on physicians' recommendations for cardiac catheterization. New England Journal of Medicine. Feb 25; 1999 340(8):618-626. [PubMed: 10029647]

37. van Ryn M. Research on the provider contribution to race/ethnicity disparities in medical care. Medical Care. Jan; 2002 40(1):140-151.

38. Kales HC, Neighbors HW, Valenstein M, et al. Effect of race and sex on primary care physicians' diagnosis and treatment of late-life depression. Journal of the American Geriatrics Society. May; 2005 53(5):777-784. [PubMed: 15877552]

39. Ghods BK, Roter DL, Ford DE, Larson S, Arbelaez JJ, Cooper LA. Patient-physician communication in the primary care visits of African Americans and whites with depression. Journal of General Internal Medicine. May; 2008 23(5):600-606. [PubMed: 18264834]

40. Broman CL. Race differences in professional help seeking. American Journal of Community Psychology. Aug; 1987 15(4):473-489. [PubMed: 3673957]

41. Huang ZHJ, Wong FY, Ronzio CR, Yu SM. Depressive symptomatology and mental health helpseeking patterns of US- and foreign-born mothers. Maternal and Child Health Journal. May; 2007 11(3):257-267. [PubMed: 17171544]

42. Kimerling R, Baumrind N. Access to specialty mental health services among women in California. Psychiatric Services. Jun; 2005 56(6):729-734. [PubMed: 15939951]

43. Neighbors HW, Jackson JS. The use of informal and formal help - 4 patterns of illness behavior in the black-community. American Journal of Community Psychology. 1984; 12(6):629-644. [PubMed: 6524587]

44. Snowden LR. Racial differences in informal help seeking for mental health problems. Journal of Community Psychology. Sep; 1998 26(5):429-438.

45. Waite R, Killian P. Health beliefs about depression among African American women. Perspectives in Psychiatric Care. Jul; 2008 44(3):185-195. [PubMed: 18577124]

46. Zuvekas SH, Fleishman JA. Self-rated mental health and racial/ethnic disparities in mental health service use. Medical Care. Sep; 2008 46(9):915-923. [PubMed: 18725845]

47. Sleath B, Shih YCT. Sociological influences on antidepressant prescribing. Social Science \& Medicine. Mar; 2003 56(6):1335-1344. [PubMed: 12600369]

48. Katz SJ, Kessler RC, Frank RG, Leaf P, Lin E, Edlund M. The use of outpatient mental health services in the United States and Ontario: the impact of mental morbidity and perceived need for care. American Journal of Public Health. Jul; 1997 87(7):1136-1143. [PubMed: 9240103]

49. Eisenberg JM, Power EJ. Transforming insurance coverage into quality health care: voltage drops from potential to delivered quality. JAMA. Oct 25; 2000 284(16):2100-2107. [PubMed: 11042759]

50. Baicker K, Chandra A, Skinner JS. Geographic Variation in Health Care and the Problem of Measuring Racial Disparities. Perspectives in Biology and Medicine. 2005 Winter; volume 48(1, supplement):S42-S53. [PubMed: 15842086]

51. Kessler RC, Zhao S, Katz SJ, et al. Past-Year Use of Outpatient Services for Psychiatric Problems in the National Comorbidity Survey. American Journal of Psychiatry. 1999; 156(1):115-123. 1999. [PubMed: 9892306]

52. Day SL. Issues in Medicaid Policy and System Transformation: Recommendations From the President's Commission. Psychiatric Services. 2006; 57(12):1713-1718. [PubMed: 17158484]

53. Billings AG, Moos RH. Comparisons of children of depressed and nondepressed parents: a socialenvironmental perspective. Journal of Abnormal Child Psychology. Dec; 1983 11(4):463-485. [PubMed: 6655148] 
54. Jaenicke C, Hammen C, Zupan B, et al. Cognitive vulnerability in children at risk for depression. Journal of Abnormal Child Psychology. Dec; 1987 15(4):559-572. [PubMed: 3437091]

55. Richters J, Pellegrini D. Depressed mothers' judgments about their children: an examination of the depression-distortion hypothesis. Child Development. Oct; 1989 60(5):1068-1075. [PubMed: 2805884]

56. Weissman MM, Gammon GD, John K, et al. Children of depressed parents. Increased psychopathology and early onset of major depression. Archives of General Psychiatry. Oct; 1987 44(10):847-853. [PubMed: 3662741]

57. Zuckerman BS, Beardslee WR. Maternal depression: a concern for pediatricians. Pediatrics. Jan; 1987 79(1):110-117. [PubMed: 3797157]

58. Kahn RS, Zuckerman B, Bauchner H, Homer CJ, Wise PH. Women's health after pregnancy and child outcomes at age 3 years: a prospective cohort study. American Journal of Public Health. Aug; 2002 92(8):1312-1318. [PubMed: 12144990]

59. Kramer RA, Warner V, Olfson M, Ebanks CM, Chaput F, Weissman MM. General medical problems among the offspring of depressed parents: a 10-year follow-up. Journal of the American Academy of Child and Adolescent Psychiatry. Jun; 1998 37(6):602-611. [PubMed: 9628080]

60. Olfson M, Marcus SC, Druss B, Pincus H Alan, M MW. Parental depression, child mental health problems, and health care utilization. Medical Care. Jun; 2003 41(6):716-721. [PubMed: 12773837]

61. McLennan JD, Kotelchuck M. Parental prevention practices for young children in the context of maternal depression. Pediatrics. May; 2000 105(5):1090-1095. [PubMed: 10790467]

62. Witt WP, Fortuna L, Wu E, et al. Children's use of motor vehicle restraints: maternal psychological distress, maternal motor vehicle restraint practices, and sociodemographics. Ambulatory Pediatrics. May-Jun; 2006 6(3):145-151. [PubMed: 16713932]

63. Mandl KD, Tronick EZ, Brennan TA, Alpert HR, Homer CJ. Infant health care use and maternal depression. Archives of Pediatrics \& Adolescent Medicine. 1999; 153(8):808-813. [PubMed: 10437752]

64. Weissman MM, Warner V, Wickramaratne P, Moreau D, Olfson M. Offspring of depressed parents. 10 Years later. Archives of General Psychiatry. Oct; 1997 54(10):932-940. [PubMed: 9337774]

65. Gallagher SK, Mechanic D. Living with the mentally ill: effects on the health and functioning of other household members. Social Science \& Medicine. Jun; 1996 42(12):1691-1701. [PubMed: 8783431]

66. Klein RF, Dean A, Bogdonoff MD. The impact of illness upon the spouse. Journal of Chronic Diseases. Apr; 1967 20(4):241-248. [PubMed: 6023232]

67. Lo Sasso AT, Rost K, Beck A. Modeling the Impact of Enhanced Depression Treatment on Workplace Functioning and Costs: A Cost-Benefit Approach. Med. Care. 2006; 44(4):352-358. [PubMed: 16565636] 
Witt et al.

Page 13

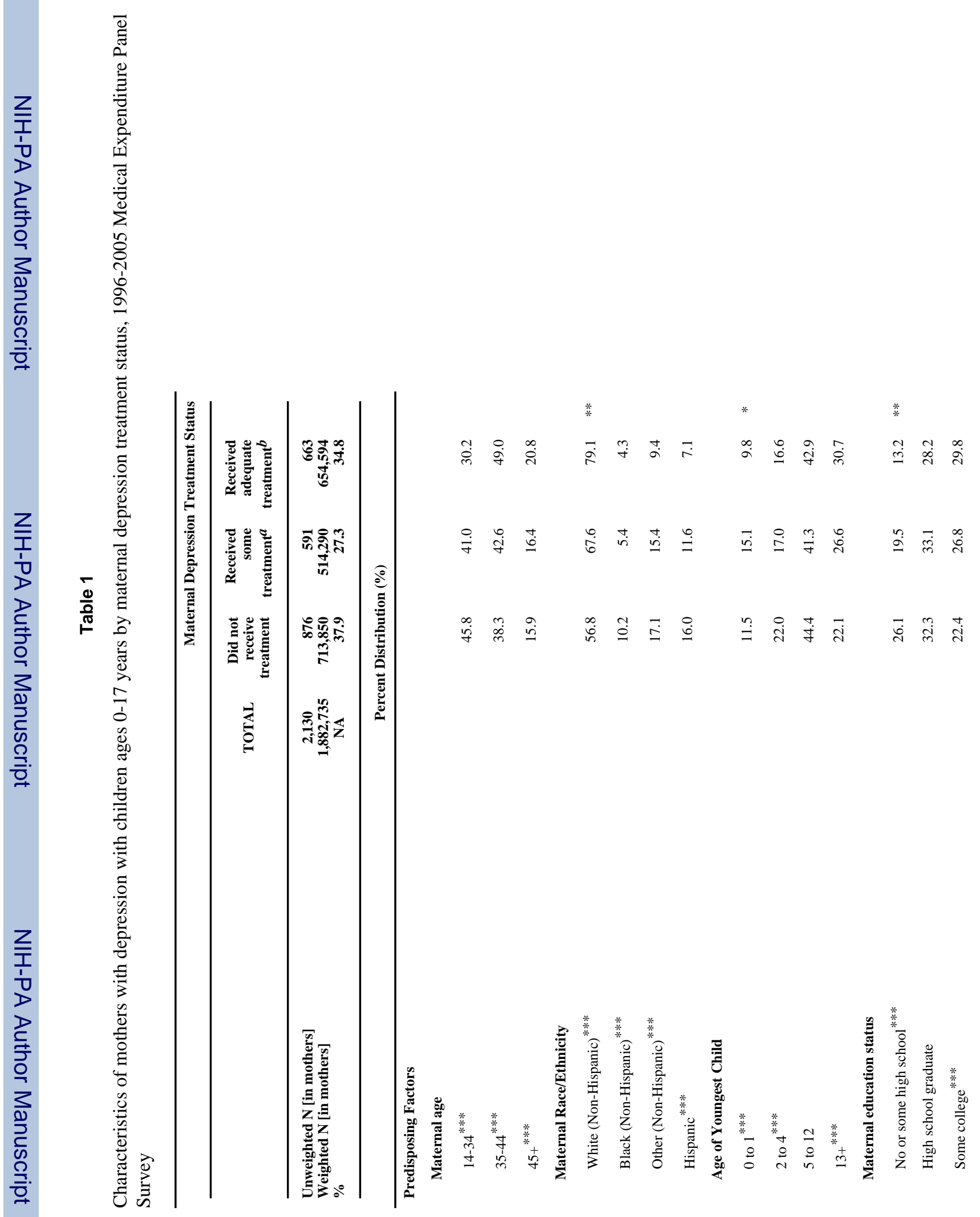

J Behav Health Serv Res. Author manuscript; available in PMC 2012 April 1. 
Witt et al.

Page 14

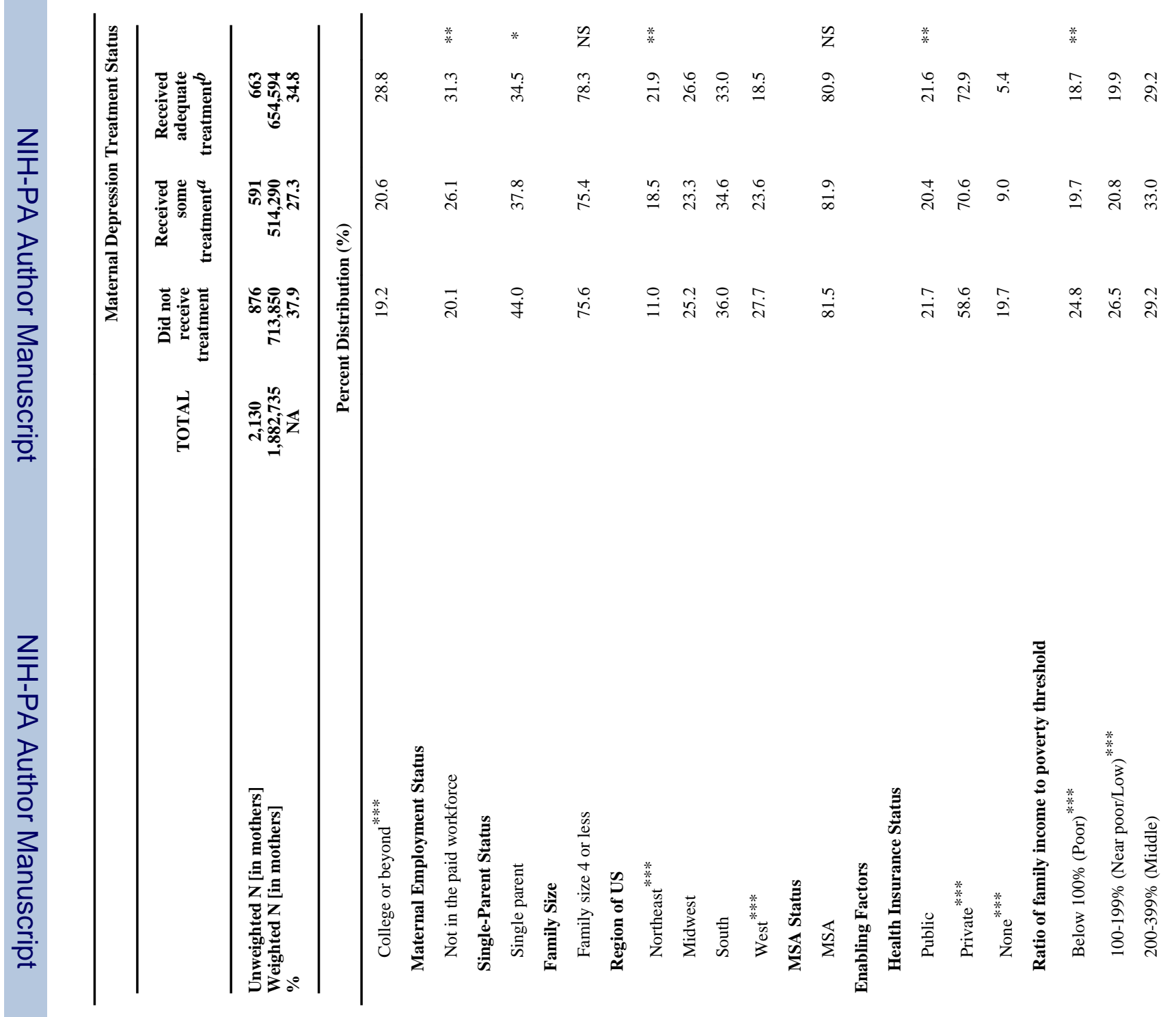

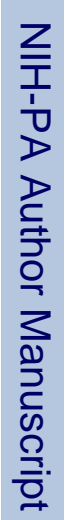


Witt et al.

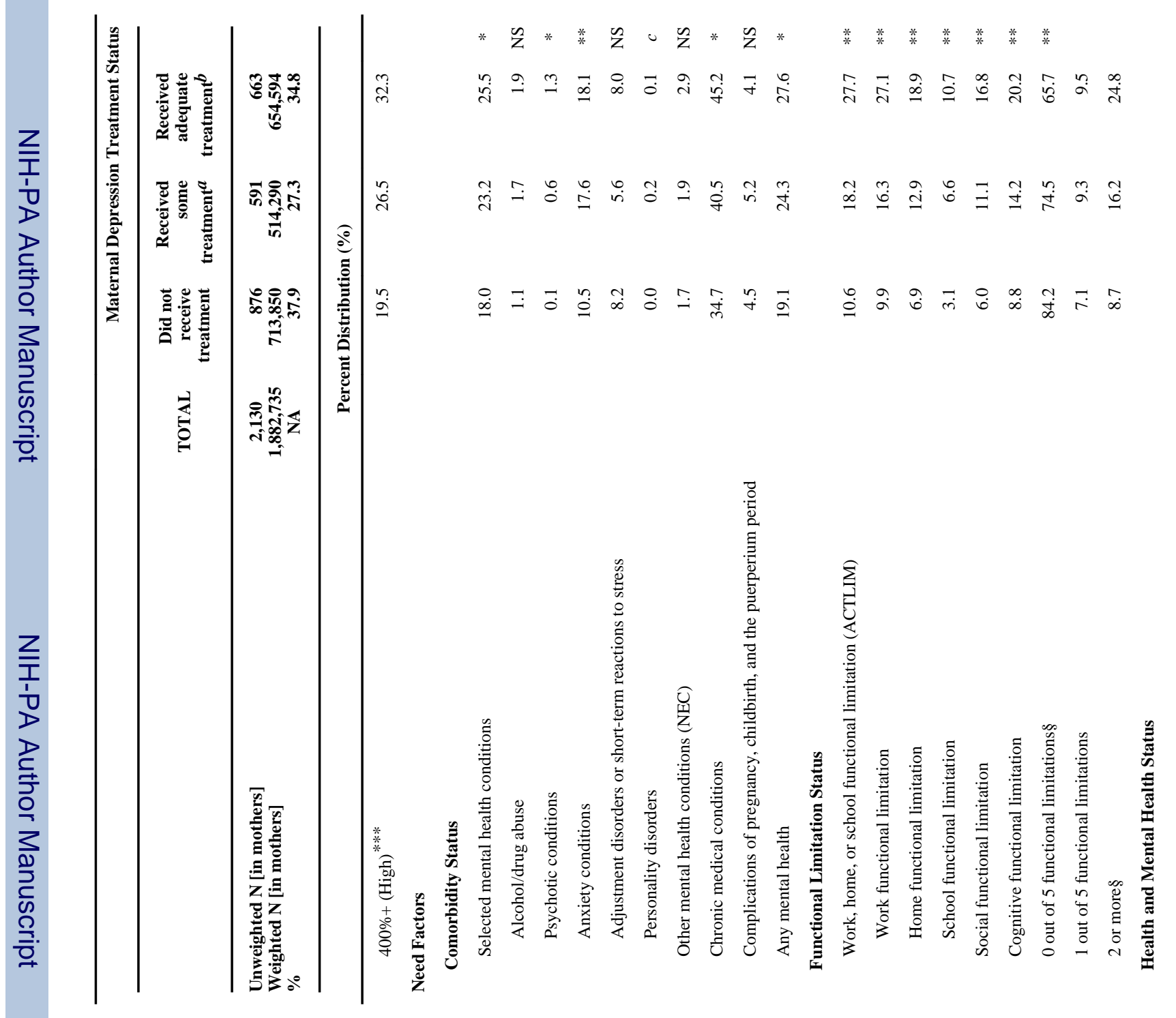

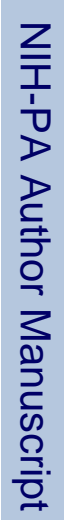


Witt et al.

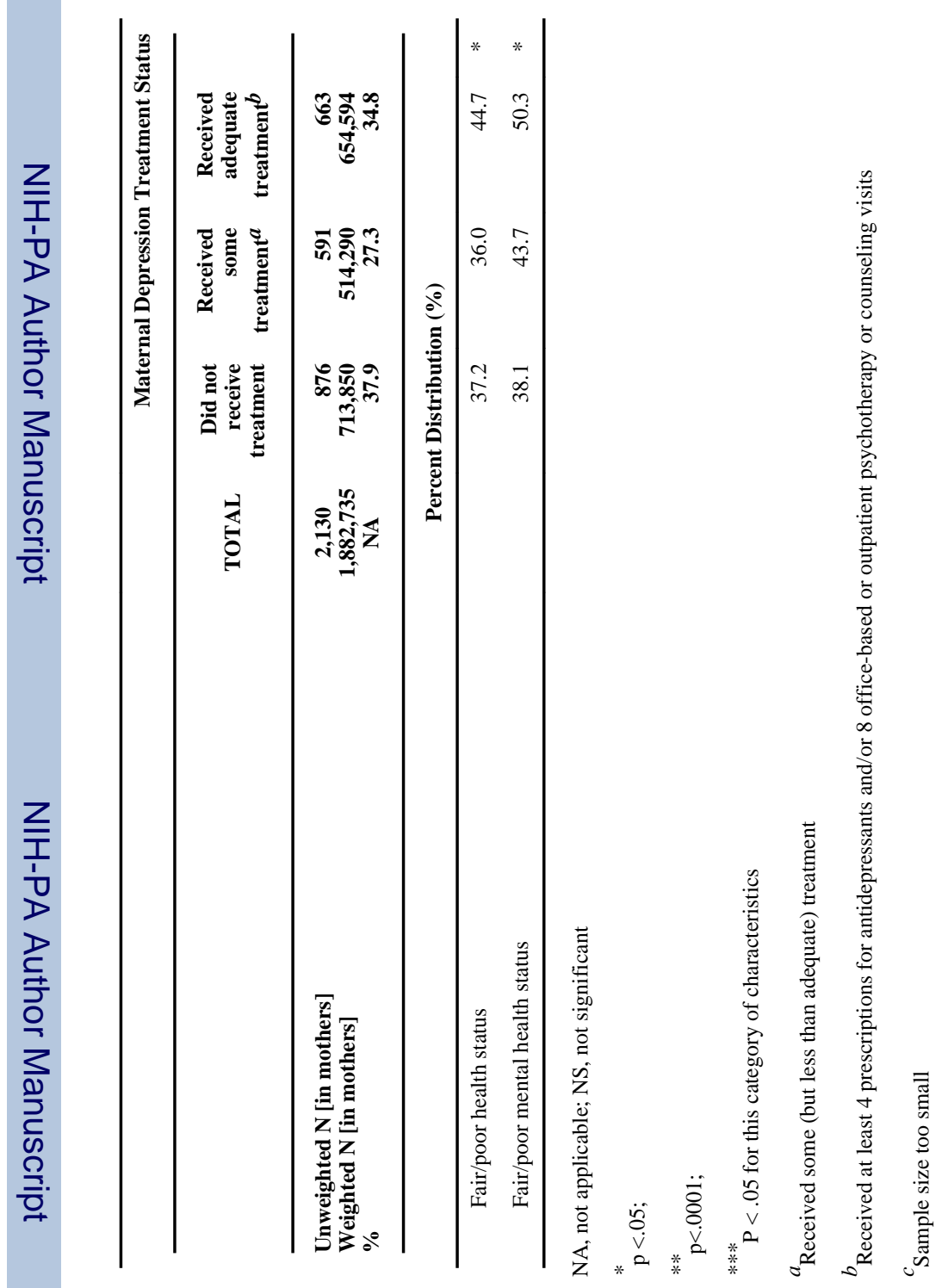

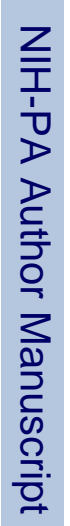




\section{Table 2}

Odds of receiving treatment among mothers with depression in the US, 1996-2005 Medical Expenditure Panel Survey

\begin{tabular}{|c|c|c|}
\hline & \multicolumn{2}{|c|}{$\begin{array}{c}\text { Dependent Variable } \\
\text { (ref. = Did not receive treatment) } \\
\end{array}$} \\
\hline & $\begin{array}{l}\text { Received some } \\
\text { treatment }\end{array}$ & $\begin{array}{l}\text { Received adequate } \\
\text { treatment } b\end{array}$ \\
\hline Independent Variables & $\underset{95 \% \mathrm{CI}}{\text { OR }}$ & $\underset{95 \% \mathrm{CI}}{\text { OR }}$ \\
\hline \multicolumn{3}{|l|}{ Predisposing Factors } \\
\hline \multicolumn{3}{|l|}{ Maternal age $($ ref. $=14-34)$} \\
\hline $35-44$ & $\begin{array}{c}1.09 \\
{[0.77,1.54]}\end{array}$ & $\begin{array}{c}1.52^{*} \\
{[1.10,2.08]}\end{array}$ \\
\hline $45+$ & $\begin{array}{c}0.81 \\
{[0.48,1.38]}\end{array}$ & $\begin{array}{c}1.10 \\
{[0.68,1.79]}\end{array}$ \\
\hline \multicolumn{3}{|c|}{ Maternal Race/Ethnicity $($ ref. = White $($ Non-Hispanic $))$} \\
\hline Black (Non-Hispanic) & $\begin{array}{c}0.40^{*} \\
{[0.24,0.65]}\end{array}$ & $\begin{array}{c}0.21^{*} \\
{[0.13,0.36]}\end{array}$ \\
\hline Other (Non-Hispanic) & $\begin{array}{c}0.67^{*} \\
{[0.47,0.95]}\end{array}$ & $\begin{array}{c}0.29^{*} \\
{[0.20,0.44]}\end{array}$ \\
\hline Hispanic & $\begin{array}{c}0.71 \\
{[0.48,1.05]}\end{array}$ & $\begin{array}{c}0.40^{*} \\
{[0.26,0.60]}\end{array}$ \\
\hline \multicolumn{3}{|c|}{ Age of Youngest Child (ref. = 13+) } \\
\hline 0 to 1 & $\begin{array}{c}1.09 \\
{[0.65,1.83]}\end{array}$ & $\begin{array}{c}0.71 \\
{[0.42,1.21]}\end{array}$ \\
\hline 2 to 4 & $\begin{array}{c}0.64 \\
{[0.40,1.03]}\end{array}$ & $\begin{array}{c}0.69 \\
{[0.44,1.08]}\end{array}$ \\
\hline 5 to 12 & $\begin{array}{c}0.76 \\
{[0.54,1.07]}\end{array}$ & $\begin{array}{c}0.73^{*} \\
{[0.53,0.99]}\end{array}$ \\
\hline \multicolumn{3}{|c|}{ Maternal education status (ref. $=$ No or some high school) } \\
\hline High school graduate & $\begin{array}{c}1.20 \\
{[0.83,1.75]}\end{array}$ & $\begin{array}{c}1.55^{*} \\
{[1.04,2.32]}\end{array}$ \\
\hline Some college & $\begin{array}{c}1.40 \\
{[0.94,2.08]}\end{array}$ & $\begin{array}{c}2.66^{*} \\
{[1.77,4.00]}\end{array}$ \\
\hline College or beyond & $\begin{array}{c}1.09 \\
{[0.71,1.67]}\end{array}$ & $\begin{array}{c}2.79^{*} \\
{[1.65,4.73]}\end{array}$ \\
\hline \multicolumn{3}{|c|}{ Maternal Employment Status } \\
\hline Not in the paid workforce & $\begin{array}{c}1.53^{*} \\
{[1.12,2.10]}\end{array}$ & $\begin{array}{c}1.86^{*} \\
{[1.35,2.56]}\end{array}$ \\
\hline \multicolumn{3}{|l|}{ Single-Parent Status } \\
\hline Single parent & $\begin{array}{c}1.00 \\
{[0.73,1.38]}\end{array}$ & $\begin{array}{c}0.90 \\
{[0.66,1.22]}\end{array}$ \\
\hline \multicolumn{3}{|l|}{ Family Size } \\
\hline Family size 4 or less & $\begin{array}{c}0.83 \\
{[0.62,1.12]}\end{array}$ & $\begin{array}{c}0.91 \\
{[0.66,1.25]}\end{array}$ \\
\hline
\end{tabular}




\begin{tabular}{|c|c|c|}
\hline & \multicolumn{2}{|c|}{$\begin{array}{c}\text { Dependent Variable } \\
\text { (ref. = } \text { Did not receive treatment })\end{array}$} \\
\hline & $\begin{array}{l}\text { Received some } \\
\text { treatment } \\
a\end{array}$ & $\begin{array}{c}\text { Received adequate } \\
\text { treatment } b\end{array}$ \\
\hline Independent Variables & $\underset{95 \% \mathrm{CI}}{\text { OR }}$ & $\begin{array}{c}\text { OR } \\
95 \% \mathrm{CI}\end{array}$ \\
\hline Northeast & $\begin{array}{c}1.86^{*} \\
{[1.20,2.88]}\end{array}$ & $\begin{array}{c}2.60^{*} \\
{[1.68,4.03]}\end{array}$ \\
\hline Midwest & $\begin{array}{c}1.06 \\
{[0.73,1.54]}\end{array}$ & $\begin{array}{c}1.50^{*} \\
{[1.06,2.10]}\end{array}$ \\
\hline South & $\begin{array}{c}1.20 \\
{[0.85,1.69]}\end{array}$ & $\begin{array}{c}1.46^{*} \\
{[1.06,2.01]}\end{array}$ \\
\hline \multicolumn{3}{|c|}{ MSA Status $($ ref. $=$ Non-MSA $)$} \\
\hline MSA & $\begin{array}{c}1.05 \\
{[0.76,1.45]}\end{array}$ & $\begin{array}{c}0.99 \\
{[0.73,1.34]}\end{array}$ \\
\hline
\end{tabular}

Enabling Factors

Health Insurance Status (ref. = None)

Public

$1.92^{*} \quad 3.73^{*}$

$[1.17,3.14] \quad[2.17,6.41]$

Private

$2.21^{*} \quad 3.31^{*}$

$[1.44,3.38] \quad[2.01,5.44]$

Ratio of family income to poverty threshold $($ Ref. $=$ Below 100\%)

100-199\% (Near poor/Low)

200-399\% (Middle)

$1.02-1.09$

$[0.68,1.52] \quad[0.74,1.59]$

$1.23 \quad 1.03$

$[0.79,1.91] \quad[0.64,1.67]$

$400 \%+$ (High)

$1.57 \quad 1.62$

$[0.93,2.63] \quad[0.97,2.72]$

Need Factors

Comorbidity Status

Other selected mental health conditions

$1.43^{*}$

$[1.06,1.91]$

$1.53^{*}$

1.21

$[0.92,1.59]$

$[1.14,2.07]$

Chronic medical conditions

Functional Limitation Status (ref. = 0 out of 5 functional limitations)

\begin{tabular}{|c|c|c|}
\hline 1 out of 5 functional limitations & $\begin{array}{c}1.43 \\
{[0.86,2.38]}\end{array}$ & $\begin{array}{c}1.55 \\
{[0.97,2.49]}\end{array}$ \\
\hline 2 to 5 out of 5 functional limitations & $\begin{array}{c}2.02^{*} \\
{[1.34,3.05]}\end{array}$ & $\begin{array}{c}3.01^{*} \\
{[1.97,4.58]}\end{array}$ \\
\hline
\end{tabular}

Health and Mental Health Status

Fair/poor health status

$\begin{array}{cc}0.77 & 1.00 \\ {[0.57,1.03]} & {[0.72,1.40]}\end{array}$

Fair/poor mental health status

1.31

$1.70^{*}$ $[0.98,1.74]$

* $<<.05$

${ }^{a}$ Received some treatment (but less than adequate) treatment

${ }^{b}$ Received at least 4 prescriptions for antidepressants and/or 8 office-based or outpatient psychotherapy or counseling visits 